\title{
DIOS, EL BENEFICIO ECONÓMICO Y LA CREACIÓN DEL ENEMIGO EN LA CORTINA DE HUMO(1997) DE BARRY LEVINSON
}

\section{GOD, ECONOMIC BENEFIT AND ENEMY'S CONSTRUCTION IN BARRY LEVINSON'S WAG THE DOG(1997)}

\author{
AUTORA \\ Paula Requeijo Rey \\ Facultad de Ciencias de la Información. Universidad Complutense de Madrid (España). \\ paulitareq@hotmail.com
}

\section{RESUMEN}

El objetivo de este estudio es analizar algunas de las claves de la estrategia de política exterior que Estados Unidos mantiene desde hace varios siglos a través de la película La Cortina de humo (Wag the Dog, Barry Levinson, 1997). El largometraje refleja cómo ésta combina aspectos antagónicos, como lo material (el beneficio económico) y lo espiritual (la religión). El "Manifest Destiny", que se formula en 1845 pero cuyo origen se remonta a la llegada de los primeros colonos británicos a comienzos del siglo XVII, permite a los estadounidenses expandirse, intervenir en los asuntos de otras potencias e iniciar conflictos teniendo a Dios de su parte. Los Estados Unidos se convierten en vigilantes de la libertad dentro y fuera de sus fronteras. Esto supone enfrentarse a aquéllos que pretenden acabar con su sistema, con su modo de vida. La construcción del enemigo se convierte en una pieza fundamental a la hora de justificar la guerra. 


\section{PALABRAS CLAVE}

La Cortina de humo - Estados Unidos - Política exterior - Destino Manifiesto Rentabilidad - Enemigo

\section{ABSTRACT}

The aim of this study is to analyze some of the foreign U.S. policy strategy key points that have remained for several centuries through the film Wag the Dog (Barry Levinson, 1997). The film shows how this strategy combines antagonistic aspects such as materiality (financial gain) and spirituality (religion). The "Manifest Destiny", formulated in 1845 but whose origins date back to the arrival of the first British settlers in the early seventeenth century, allows Americans to expand, to intervene other powers affairs and to start conflicts having God on their side. The United States becomes freedom guards inside and outside its borders. This means confronting those who seek to end their system, their way of life. Construction of the enemy becomes a key element in justifying the war.

\section{KEY WORDS}

Wag the Dog - United States - Foreign policy - Manifest Destiny - Financial gain Enemy

\section{ÍNDICE}

1. Introducción.

2. Dios, libertad y expansión territorial.

2.1 La Doctrina del "Manifest Destiny".

2.2 La Doctrina Monroe.

3. Guerra y beneficio económico.

4. La creación del enemigo. 
5. Reflexión final.

6. Bibliografía.

\begin{abstract}
"No creo que los americanos sean peores que los demás, pero tampoco me parecen mejores que los habitantes de los estados canallas a los que se refiere Bush" (Lars Von Trier, fragmento de la entrevista sobre la película Dogville (2003), página Web de los cines Golem, Madrid).
\end{abstract}

\title{
1. Introducción
}

La película La Cortina de humo (Wag the Dog, Barry Levinson, 1997) está basada en la novela de Larry Beinhart, American Heroe (1993). Se ocupa de cómo un productor de Hollywood, Stanley Motss (Dustin Hoffman), y su equipo de ayudantes fabrica una guerra ficticia para distraer la atención de la población del escándalo sexual protagonizado por el presidente de Estados Unidos a once días de las elecciones.

Una joven becaria universitaria que ha visitado la Casa Blanca acusa al presidente de acoso. Sus asesores, entre los que se encuentra Winifred Ames (Anne Heche), jefa de prensa de la Casa Blanca, se reúnen con Conrad Brean (Robert de Niro), un experto en solucionar crisis gubernamentales. Él considera que lo único que puede desplazar el interés de los medios de comunicación y, por tanto, del público, es un conflicto armado.

Albania es el país elegido para ejercer de enemigo. El motivo inventado es que hay un grupo musulmán fundamentalista que quiere destruir a Estados Unidos y está sembrando el terror en la misma Albania. Para demostrarlo, graban un vídeo en un 
plató, con una actriz que representa a una joven albanesa que huye de su pueblo en llamas con un gato en brazos. Los terroristas han matado a toda su familia y han incendiado la localidad. Motss sabe perfectamente cómo crear la pantomima bélica y, sobre todo, cómo presentársela al público para que la apoye.

Se considera que La Cortina de Humo es un gran ejemplo de: a) cómo el poder político manipula a los medios de comunicación y, estos a su vez, a los ciudadanos b) la facilidad con la que se construye una noticia falsa c) la indefensión del público frente a la desinformación d) cómo la guerra es un espectáculo televisivo más.

En este artículo, sin embargo, nos detenemos en otros aspectos importantes del filme a los que se ha prestado menos atención. La autora considera que el largometraje, a través de la parodia, ofrece varias claves de la estrategia de política exterior que Estados Unidos mantiene desde hace varios siglos. En ella se combinan elementos que, en un principio, parecen muy alejados entres sí como el beneficio empresarial y la religión. La guerra se revela como el medio perfecto por su rentabilidad económica y se justifica en nombre de Dios, que ha elegido a los Estados Unidos como vigilante de la libertad tanto dentro como fuera de sus fronteras. Aquí, la construcción del enemigo es vital.

\section{Dios, libertad y expansión territorial}

\subsection{La doctrina del "Manifest Destiny"}

La Cortina de Humo refleja la importancia de la religión en la sociedad norteamericana a través de los discursos que el presidente y su gabinete lanzan a los ciudadanos. Dios está siempre presente en ellos:

"Sé que todos nos preocupamos por el Presidente y que nuestras oraciones están con él [...] Queridos compatriotas agradezco a Dios 
misericordioso y estoy seguro de que cada uno de nosotros agradecerá a ese poder supremo, sea cuál sea nuestro concepto de ese poder, porque la paz esté próxima".

Dios también forma parte de la canción que Motss encarga al músico Johnny Dean (Willie Nelson) para apoyar la supuesta intervención militar en Albania. La letra dice lo siguiente:

"Hoy como ayer no renuncies nunca a tu fe, cuando más necesitas lo que hay que tener. Tus padres te dieron este país, al sembrar un gran jardín. Cuidar nuestro modo de vida, cuidar esta patria feliz. No queda ya rival, sois quien manda aquí si Dios lo quiere así. Cuidar esta América libre, sí, América, sí. Pisan tus pies una roca en libertad, no hay otro pueblo que viva así. Escrito está: libertad, el derecho a ser feliz. Libres hasta el fin. Cuidar nuestro modo de vida, cuidar nuestra patria feliz".

Del tema se desprende una idea principal: Dios quiere que Estados Unidos luche contra aquéllos que amenacen su sistema político. Un sistema cuya razón de ser es la libertad. Los nortemericanos no eligen por sí mismos enfrentarse a una nación o expandirse por un determinado territorio. Se trata de una imposición y un derecho divinos: "Si Dios lo quiere así [...] escrito está".

Es una derivación de la doctrina del Manifest Destiny o Destino Manifiesto, que mantiene que los angloamericanos de Estados Unidos están destinados a conquistar y poblar el Norte del continente. Dios les ha impuesto un destino y un camino: proteger y extender su sistema de libertades. Walter Lippman se plantea qué hacer "si la historia se ha propuesto realmente que asumamos la responsabilidad del liderazgo" (Lippman en Orozco, 2004, p. 162). 
El editor de la revista del Partido Demócrata, John L. O'Sullivan, es el primero en utilizar el término "manifest destiny" en 1845 "para justificar la ampliación de Estados Unidos hacia el Oeste" (Calle y Merke, 2004, pp. 125-126). O'Sullivan intentaba defender la anexión de Texas frente a la injerencia de países como Francia o Inglaterra. Éstos tratan de controlar "el cumplimiento de nuestro destino manifiesto de desarrollar el continente destinado por la Providencia, para el libre desarrollo de nuestros millones (de habitantes), multiplicados cada año" (O'Sullivan en Bosch, 2005, p. 131).

Él es el padre de la expresión pero el concepto comienza a desarrollarse mucho antes. Dos de los principales ministros puritanos de Nueva Inglaterra, J ohn Winthrop y John Cotton, veían en la colonización del Nuevo Mundo un designio providencial. Winthrop, fundador de la Colonia de la Bahía de Massachussets, afirmaba que los puritanos venían "para construir la nueva Jerusalem en lo alto de la colina". Cotton aseguró a los peregrinos que partían de Southampton que "Dios los conduciría volando sobre ellos como un águila, desde la vieja Inglaterra, tierra de iniquidades, hacia la tierra prometida" (Galeano, 1994, p. 251). Los puritanos pueden, además, tomar las tierras que hasta entonces habitaban los indios porque "lo que es común a todos, no pertenece a nadie. Este pueblo salvaje mandaba sobre vastas tierras sin título ni propiedad" (Winthrop en Galeano, 1994, p. 251).

La Providencia también está detrás de la Guerra Fría. En el último párrafo de su artículo en Foreign Affairs (julio de 1947) que firma como "Mr.X", George Kennan (al que nos referimos más ampliamente en el siguiente apartado) considera que ante el desafío que la URSS plantea a los Estados Unidos:

"Un observador reflexivo [...] experimentará cierto agradacemiento a la Providencia" por "brindar al pueblo estadounidense este implacable desafío" que requiere unidad y "aceptar las responsabilidades del liderazgo moral y político que la historia 
claramente pretendía que asumiera [...]. Es "la mejor prueba de calidad nacional' (Kennan, 1947, p. 11).

Al cumplir simplemente con un destino que Dios les marca los americanos ya tienen la justificación moral perfecta para expandirse e intervenir en los asuntos de otras potencias. Porque por encima de Dios, ente supremo, no hay nada. En Cortina de Humo, Stanley Motss también cree que Dios está de su parte. En un momento de la película dice a sus colaboradores: "Si Dios quiere, en ocho días os guiaré al nuevo camino".

\subsection{La Doctrina Monroe}

El Manifest Destiny se complementa con la Doctrina Monroe, enunciada por el Presidente James Monroe (1758-1831), en su discurso del 2 de diciembre de 1823 ante el Congreso. Conocida por la fórmula "América para los americanos" incluye una declaración de principios que, con modificaciones, guiará la política exterior de Estados Unidos desde entonces hasta nuestros días. Habría que esperar 30 años, hasta 1853, para que la prensa comenzara a llamarla Doctrina de Monroe. Destacamos tres puntos de la misma: a) ninguna potencia europea debe colonizar América b) Europa no intervendrá en los asuntos de los gobiernos de América c) Estados Unidos no se entrometerá en las cuestiones europeas a menos que se amenacen 0 invadan sus derechos.

El objetivo principal era alejar América del interés europeo y sustituir su influencia en la zona por la de Estados Unidos. Esta idea ya formaba parte de algunas cartas escritas antes de que el presidente compareciese ante el Congreso: a) la que Thomas J efferson envió a William Short el 4 de agosto de 1820 b) la que el ministro de exteriores británico, George Canning, envió al embajador norteamericano en Londres, Richard Rush, el 16 de agosto de 1823 c) la que Thomas Jefferson envió al Presidente Monroe el 24 de octubre de 1823. 
La Doctrina Monroe insiste en la injerencia pero también "expresa la temprana presencia de una ambición expansionista [...]" (María Elena González en VV.AA., 2002 , p. 310). Buscaba "la conservación de la integridad norteamericana y garantizar el intervencionismo de los Estados Unidos en Iberoamérica" (Morales Padrón, 1987, p. 48). El primer presidente de Estados Unidos, George Washington, ya explicó en su discurso de despedida en 1796 la necesidad de "construir un estado asegurando ( $y$ luego expandiendo) su territorio" (Calle y Merke, 2004, p. 125).

Desde su formulación, la Doctrina Monroe se ha ido ampliando a través de diversos corolarios. Destacamos el Corolario del presidente Theodore Roosevelt en su mensaje al Congreso el 6 de diciembre de 1904. Este corolario sustituye el poner fin a la injerencia europea en América, idea principal de la Doctrina, por la intervención estadounidense en el hemisferio occidental. Roosevelt justifica así el papel de Estados Unidos como "policía internacional":

"No es cierto que Estados Unidos quiera conquistar otras tierras o se entretenga con cualquier proyecto respecto a otras naciones del hemisferio occidental, salvo en el de su bienestar. Todo lo que este país desea es que reinen la estabilidad, el orden y la prosperidad entre nuestros países vecinos. Cualquier país cuya población se comporte bien puede contar con nuestra profunda amistad. Si una nación demuestra que sabe actuar con una eficiencia y una decencia razonables en materias sociales y políticas, si mantiene el orden y el respeto a sus obligaciones, no tiene por qué temer una intervención de Estados Unidos. La injusticia crónica o la impotencia que se refleja en el relajamiento general de los vínculos de una sociedad civilizada, podrían exigir, a fin de cuentas, en América o fuera de ella, la intervención de una nación civilizada y, en el hemisferio occidental, la adhesión de Estados Unidos a la Doctrina de Monroe podría obligar a 
Estados Unidos, aunque en contra de sus deseos, en casos flagrantes de injusticia o impotencia, a ejercer un poder de policía internacional" (Roosevelt en José Moya, 1994, p. 417).

Aunque el conflicto que nos plantea La Cortina de humo es ficticio, refleja cómo los Estados Unidos han utilizado "el derecho de propia conservación" a lo largo de varios siglos para intervenir en los asuntos de otras potencias e iniciar guerras (Morales Padrón, 1987, pp. 48 y 49). Stanley Motss considera que el mejor argumento para que la población apoye la guerra es que Albania quiere "destruir su modo de vida". Una forma de vida, la democracia, que encarna la libertad y hace felices a los ciudadanos. La canción de apoyo a la guerra habla de "cuidar nuestra patria feliz" y de que "no hay ningún otro pueblo que viva asi". De nuevo, estamos ante una idea que viene de lejos.

"[...] A la defensa del nuestro (sistema político), al que se ha llegado con la pérdida de tanta sangre y riqueza, que ha madurado por la sabiduría de sus más ilustrados ciudadanos, y bajo el cual hemos disfrutado de una felicidad no igualada, está consagrada la nación entera (James Monroe, 1823, fragmento del séptimo mensaje anual del presidente al Congreso el 2 de diciembre de 1823).

\section{Guerra y beneficio económico}

Fingir una guerra se presenta como la estrategia perfecta, no sólo porque desviará la atención de la población sobre el escándalo sexual, sino porque generará montones de dinero. Winifried Ames, jefa de prensa del presidente, afirma que crear un conflicto "es fantástico y lo es porque es rentable". Se diseñan distintos productos vinculados al posible enfrentamiento con Albania $y$, a través de varias estrategias de marketing, se ponen a la venta. 
Inventan a un héroe de guerra, norteamericano como ellos, para que la proximidad geográfica fortalezca las emociones: "Old Shoe". Es un pobre ciudadano al que no deben abandonar. Tampoco a su familia. Su deber es apoyarle y seguir con la guerra. Porque cualquiera de nosotros podría ser ese soldado o su madre. "Old Shoe" se ha quedado atrapado en el territorio enemigo, un lugar extraño, lejos del mundo que conoce, amable y civilizado. Apartado de su familia, secuestrado por unos individuos atroces sin ningún tipo de moralidad o escrúpulos ha escrito un mensaje en su jersey: "iCoraje mamá!".

No es casual que se haga referencia al coraje: hay que luchar, ser valientes porque nuestras ideas, nuestros principios, que son los acertados están en peligro. Una vez que consiguen introducirlo en los corazones de la gente, es el momento de pasar a la parte racional, a la del beneficio económico que, claro, se oculta a la población. El negocio del dinero es uno de los principales motivos para emprender un conflicto.

Crean pulseras, discos con canciones de apoyo al héroe, camisetas (con el lema "Fuck Albania" -Jode a Albania-) y zapatos (la zapatilla "air leopardo"). Instan a la gente a que cuelgue su viejo calzado en los árboles como símbolo de su apoyo a "Old Shoe". "¿Qué lograremos con esa bobada de colgar los zapatos en los árboles?" - pregunta uno de los hombres del presidente. "Pues que tiren los viejos y se compren unos nuevos, ahí está el negocio" - responde Motts. Las empresas apoyan la guerra porque reactiva sus negocios. El gran ejemplo aquí es la Asociación de Productores de Calzado. Uno de los colaboradores sugiere cambiar de enemigo: "¿Por qué no Italia? Puedo conseguir mucho más dinero con Italia que con Albania”. Hay que enfrentarse contra el que mayores beneficios nos proporcione.

La guerra es buena para las empresas, para el presidente y para la población, que puede emocionarse, comprometerse y ponerse en el lugar del héroe de guerra 0 de la pobre niña indefensa. 
El filme parodia uno de las ideas de Paul Nitze, director de la Oficina de Planificación Política del Departamento de Estado a comienzos de la década de los 50. Nitze afirma que "el mismo gasto militar [...] estimula la economía e incrementa el nivel de vida [...] y el producto nacional bruto" (Orozco, 2004, pp. 165 y 166). J unto a sus colaboradores elabora el documento NSC-68 (Informe 68 del Consejo de Seguridad Nacional), que se edita en abril de 1950. En él se pone el ejemplo de cómo durante la II Guerra Mundial el funcionamiento de la economía norteamericana "se acerca a la plena eficiencia" proporcionando "enormes recursos" y "un elevado estándar de vida" (Nitze en Orozco, 2004, p. 166). El texto, que guiará la política estadounidense durante las dos décadas siguientes, ve en la URSS a un poderoso enemigo contra el que sólo cabe "revigorizar el poderío, en sentido amplio, de los Estados Unidos y el mundo libre" (Nitze en Orozco, 2004, p. 165).

\section{La creación del enemigo}

El antecesor de Nitze en la oficina de Planificación Política, George Kennan, se ocupó de caracterizar al enemigo soviético en un telegrama que envió a Washington desde la embajada de Estados Unidos en Moscú, en febrero de 1946. Conocido como "Iargo telegrama" por su extensión (8.000 palabras), en él Kennan explica que "el poderío soviético [...] impenetrable a la lógica de la razón, es altamente sensible a la lógica de la fuerza" (Kennan en Orozco, 2004, p. 161).

Bajo el seudónimo de "Mr. X", publicó en julio de 1947 un artículo en la revista Foreign Affairs (Asuntos exteriores), que incluye el contenido del telegrama. Responsable de la doctrina de la contención, no estaba de acuerdo con la militarización del conflicto y sería partidario, varios años después de enviar el famoso telegrama, de iniciar negociaciones con Moscú. Sin embargo, antes escribió al abogado bancario cercano al Pentágono James Forrestal que se preparaba desde 1944 para "impulsar el complejo Industrial-Militar" (Orozco, 2004, p. 160): 
"Tenemos aquí una fuerza política fanáticamente comprometida con la creencia de que no puede haber ningún modus vivendi permanente con los Estados Unidos, que es deseable y necesario que sea quebrantada la armonía interna de nuestra sociedad, que nuestro modo tradicional de vida sea destruido y que la autoridad internacional de nuestro Estado sea socavada para asegurar el poderío soviético" (Kennan en Orozco, 2004, p. 160).

Nitze alude a la misma idea seis años después:

"Ningún otro sistema de valores es tan irreconciliable con el nuestro, tan implacable en su propósito de destruir el nuestro, tan capaz de aprovechar en su propio beneficio las más peligrosas y divisionarias tendencias de nuestra propia sociedad [...]" (Nitze en Hernández, 2000, pp. 41 y 42 ).

En el filme, Stanley Motss mantiene esta conversación con Conrad Brane:

Stanley Motss.- ¿Por qué Albania?

Conrad Brane.- Porque...

Stanley Motss.- ¿Tienen algo que deseamos?

Conrad Brane.- Seguro...

Stanley Motss.- ¿Y qué desean de nosotros?

Conrad Brane.- ¿Libertad?

Stanley Motss.- ¿Por qué iban a querer eso?

Conrad Brane.- ¿Porque están oprimidos?

Stanley Motss.- No, no, no... A la mierda la libertad. Ellos quieren destruir al Satanás impío de los estados. Bueno, quieren destruir nuestro estilo de vida. ¿No es así? Lo es, lo es [...]. Hemos descubierto que tienen la bomba. Acabamos de descubrir que 
Albania tiene la bomba. [...] No, no. No tienen la bomba porque ellos deberían tener misiles y toda esa parafernalia. Y ellos son una pandilla de palurdos. Lo que tienen es una maleta bomba. No hacen falta misiles [...]. Unos terroristas albaneses han colocado una maleta bomba en Canadá en un intento de introducirla en Estados Unidos.

Las características del enemigo son indispensables para justificar el conflicto. En los tres casos que acabamos de presentar su imagen se construye de forma similar. Es un fanático, ciegamente entusiasmado con la idea de "quebrantar la armonía interna de nuestra sociedad", "destruir nuestro modo tradicional de vida", "nuestro estilo de vida", "nuestro sistema".

En su territorio no existe el principio fundamental: la libertad. El documento NSC-68 presenta a los norteamericanos y sus aliados como los representantes de la misma frente a la Unión Soviética y sus potencias satélites, que encarnan la esclavitud: "Hay un conflicto básico entre la idea de Libertad bajo un Gobierno de Leyes y la idea de Esclavitud bajo la siniestra oligarquía del Kremlim [...]" (Nitze en Hernández, 2000, pp. 41 y 42 ).

El antagonista es también un ser despiadado. No importa que para demostrar su falta de humanidad, su crueldad y barbarie, haya que mentir. Es difícil que los ciudadanos lleguen a saber que se trata de un montaje como Brane les explica a Winifred Ames y Motss:

Conrad Brane.- Durante el gobierno de Reagan, 240 marines murieron en Beirut. A las 24 horas, invadimos Granada. Ese era su modus operandi, cambiar la historia y el enfoque. No es un concepto nuevo. Despiértame cuando aterricemos y seguiremos hablando.

Winifred Ames.- No, espera. No podemos tener una guerra.

Conrad Brane.- No tendremos ninguna guerra sino la apariencia de una guerra. 
Winifred Ames.- Tampoco podemos permitirnos eso.

Conrad Bink.- ¿Qué nos costaría?

Winifred Ames.- Pero ellos se enterarían.

Conrad Brane.- ¿Quién va a enterarse? ¿El pueblo americano?

Winifred Ames.- Exacto.

Conrad Brane.- ¿Quién se lo dirá? Dime.

Winifred Ames.- Ah... No sé.

Conrad Brane.- ¿De qué se enteraron en la Guerra del Golfo? Un vídeo de una bomba que cae y hace volar un edificio. Podía ser una maqueta.

Winifred Ames. - ¿Realmente quieres ir a una guerra?

Conrad Brane.- En general esa es la idea.

Conrad Brane- Stan, sea realista. ¿Quién mató a Kennedy? Yo leí el informe Warren. Decía que le había matado un conductor borracho. Usted vio lo del Golfo. ¿Qué vio día tras día? La bomba inteligente que cayó por una chimenea. ¿Era verdad? Yo estaba allí cuando rodaron esa secuencia. La rodaron en un estudio de Virginia con una maqueta del edificio a escala.

Stanley Motts.- ¿Es cierto?

Conrad Brane.- ¿Cómo podemos saberlo? ¿Me entiende ahora?

Crean un vídeo en el que una niña con un gatito en su regazo huye de un pueblo en llamas incendiado por los terroristas albaneses. Estos individuos han asesinado a toda su familia y le han obligado a presenciarlo. Cuando lo difundan todas las televisiones, ¿quién no va a sentir compasión por esa inocente muchacha que ha visto morir a los suyos y a la que han forzado a abandonar su hogar?

Motss es realmente agudo a la hora de idear el vídeo. No trata de convencer a la población con un argumento racional sino que persuade a través de las pasiones. Los sentimientos pueden con las razones, son determinantes a la hora de tomar una decisión o posicionarse. Él lo sabe y no duda en explotarlo al máximo. 
De vuelta a la realidad, durante la Guerra del Golfo (1990-1991), el gobierno estadounidense y el de Kuwait nos dan un buen ejemplo de cómo fabricar un enemigo desalmado. Las cámaras recogen la terrible historia de la adolescente de 15 años Nijirah-al Sabah. En una sesión del Congreso de Estados Unidos para aprobar la intervención en Irak, Nijirah afirma, entre lágrimas, que presenció cómo los soldados iraquíes entraron en un hospital y desenchufaron varias incubadoras dejando morir a los 312 bebés prematuros que estaban dentro. Añadió incluso que los habían tirado al suelo. La noticia se emitió en todo el mundo. Después, se descubrió que todo era falso y que Nijirah era la hija del embajador de Kuwait en Washington, Saud Nasir Al Sabah. La empresa de relaciones públicas Hill \& Knowlton (la mayor del mundo) se encargó de crear la historia (Pizarroso, 2005, p. 127).

A la obsesión del otro por propinar un ataque mortal a su modelo (la democracia), su crueldad y amoralidad se controponen la libertad y los principios más elevados del pueblo estadounidense. Esta lucha entre el Mal y el Bien se repite a lo largo de la historia de Estados Unidos. Orozco explica que:

“[...] Los Estados Unidos pueden recomponer el orden mundial de acuerdo al cándido realismo atribuible a George Washington o Thomas Jefferson y a los que como ellos se visualizaron a sí mismos como a hombres buenos, rotos por el océano de maldad proveniente de Europa " (Orozco, 2004, p. 46).

Cuando el enemigo era el viejo continente, que podía minar la capacidad de influencia de Estados Unidos en América, Thomas J efferson afirmaba: "Mientras ésta (Europa) trabaja para convertirse en el domicilio del despotismo, nuestro esfuerzo debe ser ciertamente hacer nuestro hemisferio el de la libertad" (Thomas J efferson, 1823, fragmento de la Carta de J efferson a Monroe). 
Ignacio Ramonet señala el claramente enfrentamiento entre "los buenos -ismos ( $y$, ahora, -ciones) el mercabilismo, el librecambismo, el monetarismo, la globalización, la desregulación, la privatización y la liberalización" y "os malos -ismos: racionalismos, nacionalismos y fundamentalismos" (Ramonet en Orozco, 2004, p. 27). En La Cortina de Humo el enemigo es Albania porque "desde hace tiempo es un centro del terrorismo mundial".

\section{Reflexión final}

La película muestra cómo la estrategia de política exterior norteamericana, que se mantiene a lo largo de la historia del país, combina dos aspectos antagónicos: lo material y lo espiritual. Se unen el interés económico y la rentabilidad (a través del diseño de un plan objetivo que establezca los medios necesarios para alcanzar un fin) con la apelación constante a Dios. Los norteamericanos han ideado un sistema en el que el conflicto entre moralismo e interés nacional se soluciona uniendo ambos.

Su justificación está basada en una especie de superioridad moral de origen divino que se aplica a objetivos puramente materiales. Como ya hemos expuesto, los primeros ejemplos los encontramos en los colonos británicos que llegan a Norteamérica a comienzos del siglo XVII. Aquí está el origen de algunos de los principales mitos que alimentan la conciencia del hombre estadounidense como el del "Destino Manifiesto". La colonización del Oeste fue facilitada por el ansia de progreso económico de los ciudadanos y por el progreso tecnológico pero también por la acción gubernamental y la justificación moral, que instrumentalizaron muy hábilmente las aspiraciones del pueblo.

Sorprendentemente, con todo el tiempo que ha pasado desde entonces, la idea no pierde fuerza y sigue vigente en la política exterior actual. A lo largo de los siglos, diferentes naciones han tenido que hacer frente al fracaso de sus empresas. Esas 
caídas han ido unidas al declive de ciertos conceptos. Sin embargo, la breve historia de los Estados Unidos es la de un ascenso más o menos constante. Los problemas surgidos hasta el momento no han impedido que se convierta en la primera potencia mundial. Por ello, mientras siga proporcionando triunfos 0 , por decirlo como ellos, mientras sea el camino directo a sus objetivos, esta estrategia de política exterior perdurará.

\section{Bibliografía}

BOSCH, Aurora (2005): Historia de Estados Unidos (1776-1945). Editorial Crítica. Barcelona.

CALLE, Fabián y MERKE, Federico (2004): "La estrategia de seguridad nacional de Estados Unidos en la era unipolar" en Agenda Internacional Visión del Sur. Fundación Internacional Visión del Sur, Argentina, Año 1, número 3, diciembre 2004, enerofebrero 2005.

GALEANO, Eduardo (1994): Memoria del Fuego 1. Los nacimientos. Siglo XXI. Madrid.

HERNÁNDEZ, Fernando (2000): Historia de la OTAN. De la Guerra Fría al intervencionismo humanitario. Los Libros de la Catarata. Madrid.

JEFFERSON, Thomas (1823): "Carta de Jefferson a Monroe". Consultado el 20 de enero de 2005. Disponible en: www.filosofia.org/ave/001/a264.htm

KENNAN, George (1947): "Las fuentes de la conducta soviética" en Foreign Affaire, volumen 24, número 4. Consultado el 20 de enero de 2005. Disponible en: http://es.scribd.com/doc/2260360/Las-fuentes-de-la-conducta-sovietica 
MONROE, James (1823): "Fragmento del séptimo mensaje anual del presidente James Monroe al Congreso el 2 de diciembre de 1823". Consultado el 20 de enero de 2005. Disponible en: www.filosofia.org/ave/001/a264.htm

MORALES, Francisco (1987): Historia de unas relaciones difíciles (Estados Unidos América española). Publicaciones de la Universidad de Sevilla. Sevilla.

MOYA, José (1994): Una empresa llamada Estados Unidos. Ediciones de la Torre. Madrid.

OROZCO, José Luis (2004): El siglo del pragmatismo. Universidad Nacional Autónoma de México. México D.F.

VV.AA. (2002): Memorias de América Latina. Fondo Editorial de Humanidades y Educación, Universidad Central de Venezuela. Caracas, Venezuela.

VON TRIER, Lars (2004): Entrevista en la página Web de los Cines Golem sobre la película Dogville, Disponible en:

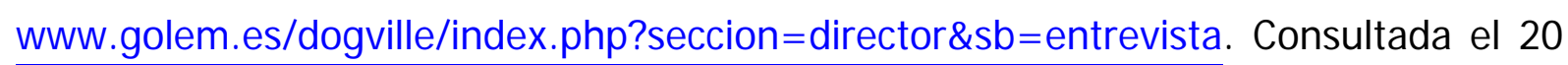
de enero de 2006. 